\title{
Active and passive avoidance conditioning: A direct comparison'
}

\author{
WILLIAM H. CALHOUN and ROBERT J. \\ MURPHY, University of Tennessee, \\ Knoxville, Tenn. 37916
}

Mice were trained in a single apporatus with either active- or passive-conditioning procedures, and retention was assessed with either procedure. For one passive and three active training trials, retention was evidenced with either retesting procedure. This indicates that the conditioning effect is independent of the retesting method. Therefore, this procedure is useful in separating effects of treatments on performance and those on conditioning.

In this paper, we will show that two kinds of avoidance conditioning, active and passive, can be conducted in the same apparatus, and that comparable scores for retention can be obtained with either method. This is an important finding relevant to the use of avoidance conditioning as a behavioral test of effects of experimental treatments.

In some experiments, only one type of avoidance conditioning has been used, yet the results are often assumed to apply to avoidance conditioning in general. For example, Plotnikoff (1966a, b, 1967) showed that rats treated with Cylert (magnesium pemoline) were superior in a jump-out avoidance task (active avoidance) to control animals. He concluded that the drug improved avoidance conditioning. To reach such a general conclusion with a restricted set of operations is unwarranted. This was clearly shown when Gurowitz, Lubar, Ain, \& Gross (1967) found that Cylert distupted passive avoidance.

In other cases, the effect of a treatment was different, depending on the type of avoidance conditioning used. For example, AcCleary (1961) showed that rats and cats with lesions in the septal area of the brain were superior in shuttle-box learning (active avoidance), while the lesioned animals were inferior in learning to inhibit approaching a food cup following repeated punishment (passive avoidance). Rats and mice treated with scopolamine hydrobromide were found deficient in passive avoidance by several investigators (Meyers, 1965; Bohdanecký \& Jarvik, 1967; Calhoun \& Smith, 1968), yet drug-treated mice made more avoidance responses in a shuttle box (Oliverio, 1967). It is possible that activeand passive-avoidance conditioning are basically opposed processes, and such differential effects would be expected.
However, the apparatus and procedures used for the two types of conditioning were different. These differences may be responsible for the seemingly opposed effect of the experimental treatment on the performance of the animals in the two types of tasks.

In terms of Mowrer's analysis of avoidance conditioning (1960, pp. 22-33), the basic component is classical conditioning through the pairing of the aversive stimulus and the cues present in the environment. Following a number of such pairings, the cues alone will serve to elicit anticipatory responses that serve to motivate either the escape response as is required in active avoidance (jumping the hurdle before the shock is presented) or the inhibition of the approach response, as is required in passive avoidance. If this analysis is correct, a treatment that interferes with the conditioning should lead to poor learning with either type of avoidance behavior. However, some treatments make the animal more active or excitable. In such a case, the animal may appear to learn active avoidance more quickly than normal animals, because it is more responsive to the shock or to the conditioned stimulus. However, an active or excited animal may appear to learn passive avoidance poorly, merely because of increased locomotor activity, or other factors interfering with immobility.

In any event, it is not possible to know what factors are involved in the performance of animals on avoidance conditioning when markedly different apparatus and procedures are used. Therefore, we

Table 1

Retention of Aversive Conditioning in Terms of Latency to Enter (Passive) or Escape (Active) from the Compartment in Which Shock Had Been Administered with Different Training Conditions (Male ICR Mice)

\begin{tabular}{lcccrr}
\multicolumn{2}{c}{\begin{tabular}{c}
\multicolumn{2}{c}{ Training Conditions } \\
No.
\end{tabular}} & & \multicolumn{2}{c}{ Retention* } \\
\cline { 5 - 6 } Type & Trials & N & Type & $\begin{array}{r}\text { Meas. } \\
\text { (sec) }\end{array}$ \\
\hline P-E & 1 & 25 & P & 300.0 \\
P-NE & 1 & 30 & A & 12.0 \\
& & 15 & A & 300.0 \\
A-E & 1 & 9 & P & 21.5 \\
& 3 & 7 & & 300.0 \\
& 1 & 9 & A & 49.5 \\
& 3 & 7 & & 6.5 \\
A-NE & 1 & 9 & P & 39.0 \\
& 3 & 7 & & 210.0 \\
& 1 & 9 & A & 44.5 \\
& 3 & 7 & & 13.0 \\
\hline
\end{tabular}

* Maximum latency $300.0 \mathrm{sec}$ undertook the development and testing of an apparatus that could be used to train animals on either active or passive procedures, and to allow for the testing of retention with either procedure, regardless of the training methods.

\section{APPARATUS}

The apparatus consisted of a two-compartment box, one $15.2 \times 15.2 \mathrm{~cm}$, fitted with a grid floor. Attached was a small compartment $(7.6 \times 10.2 \mathrm{~cm})$, which connected with the grid compartment by a small door. Shock was provided by a constant-current dc power source. Male ICR mice, obtained from Cumberland View Farms, Clinton, Tenn., were Ss. PROCEDURES

The training procedures were: (1) Passive-escape (P-E). The mouse was placed into the small compartment with the door closed. After 2-3 sec, the door between the two chambers was opened and the animal allowed to enter the grid compartment. This occurred within a few seconds. The door was closed and the mouse received $1 \mathrm{~mA}$ of scrambled foot shock. After $10 \mathrm{sec}$ of shock, the door was reopened and the animal allowed to escape the shock by re-entering the small compartment. (2) Passive-nonescape (P-NE). Same procedures as P-E except that after $10 \mathrm{sec}$, the shock was terminated and the mouse removed from the grid compartment. (3) Active-escape (A-E). The mouse was placed directly into the grid compartment with the door closed. After 2-3 sec, the shock was started. After $10 \mathrm{sec}$ of shock, the door was opened and the animal allowed to escape the shock by entering the small compartment. (4) Active-nonescape (A-NE). Same as A-E except that the door was never opened. The mouse was removed after the $10 \mathrm{sec}$ of shock.

Twenty-four hours later the mice were retested, without shock. The passive retest consisted of placing the mouse into the safe compartment, opening the door, and recording the latency to enter the grid compartment. A 5-min maximum was allowed. For the active retest, the $S$ was placed into the grid compartment, the door opened, and latency to leave was recorded. RESULTS AND DISCUSSION

The results are presented in Table 1 . It can be seen that the P-E training conditions produced reliable and substantial learning. When retention was assessed by passive procedures, the median latency was $300 \mathrm{sec}$. Of the 25 mice tested, only 2 entered the grid compartment during the 5-min test period. With the active retest procedure, the escape latency was low $(12.0 \mathrm{sec})$, showing that the mice quickly left the compartment in which they had previously been shocked. Of the 19 mice tested, the longest latency was $20 \mathrm{sec}$. 
With P-NE procedures, the results were comparable. Only 4 of the 30 passive tested animals entered the compartment on the retest day, indicating a strong effect of the conditioning, highly similar for P.E trained animals. For the active tested mice, the longest latency was $30 \mathrm{sec}$, again showing strong conditioning. In summary, for passive training procedures, it is clear that the mice "learned" the shock-grid-compartment relation in that animals placed into the adjacent safe compartment did not enter the previously aversive situation, and animals placed directly into that situation escaped rapidly.

With the active training condition, a single trial was not adequate to produce substantial learning, regardless of the retention test. For one training trial, the latency to enter the grid compartment on the passive test for the escape and nonescape groups were fairly similar, and within the range of the latency to escape from the grid compartment with the active test. This would indicate that the single shock did not affect the tendency of the mice to go from one to the other compartment. It is commonly found that active avoidance learning requires more trials than passive avoidance learning, so the number of training trials was increased. For three trials, the data were similar to those with the single passive trial. In summary, for active training, substantial learning can be demonstrated for both active and passive retest, but only more than one shock trial.

The major point is that the mice tested demonstrated "memory" of the shock experiences for both assessment procedures. This method should provide a strong test of treatment effects. For example, if a treatment interferes with the conditioning process, retest performance should be consistently poorer with both test procedures. If, however, the effect is not consistent, other factors must be influencing the performance.

\section{REFERENCES}

BOHDANECKÝ, Z., \& JARVIK, M. E Impairment of one-trial passive avoidance learning in mice by scopolamine, scopolamine methylbromide, and physostigmine. International Journal of Neuropharmacology, $1967,6,217-222$

CALHOUN, W. H., \& SMITH, A. A. Effects of scopolamine on acquisition of passive avoidance. Psychopharmacologia, 1968, 13, 201-209.

GUROWITZ, E. M., LUBAR, J. F., AIN, B. R., \& GROSS, D. A. Disruption of passive avoidance learning by magnesium pemoline. Psychonomic Science, 1967, 8, 19-20.

MCCLEARY, R. A. Response specificity in the behavioral effects of limbic system lesions in the cat. Journal of Comparative \& Physiological Psychology, 1961, 54,605-613.

MEYERS, B. Some effects of scopolamine on a passive avoidance response in rats. Psychopharmacologia, 1965, 8, 111-119.

MOWRER, O. H. Leaming theory and behavior. New York: Wiley, 1960.

OLIVERIO, A. Contrasting effects of scopolamine on mice trained simultaneously with two different schedules of avoidance conditioning. Psychopharmacologia, 1967, 11, 39-51.

PLOTNIKOFF, N. Magnesium pemoline: Enhancement of learning and memory of a conditioned avoidance response. Science, 1966a, 151, 703-704.

PLOTNIKOFF, N. Magnesium pemoline: Enhancement of memory after electroconvulsive shock in rats. Life Science. 1966b, 5, 1495-1498.

PLOTNIKOFF, N. Pemoline and magnesium hydroxide: Memory consolidation following acquisition trials. Psychonomic Science, 1967 9, 141-142.

\section{NOTE}

1. Supported in part by Grant $12770-02$ from NIMH. These data were presented at the Psychonomic Society, St. Louis, 1968.
Neither magazine training nor key shaping was necessary to establish stable response rates for six Indian elephants, since they readily manipulated any novel object and adapted slowly to anything moveable or noise-producing. 3

The Oscar fish (Astronotus ocellatus) requiręs no pairing of key light with reinforcer to generate key responses. It strikes readily at objects, but adapts rapidly and autoshapes in one session if previously magazine trained (Squier, 1969). However, six mouthbreeders (Tilapia, probably mossambica) proved impossible to train under identical conditions.

This study undertook autoshaping of both magazine and key responses in fishes, since magazine training was found to requir? several sessions for at least eight fish species. METHOD

Two species of fish were caught in brackish water in Paiko Swamp, Oahu. They were maintained 2 to 4 months in community tanks of sea water, fed dry trout food, and moved to individual tanks for experimentation. Tilapia mossambica were 3 to 4 in. long and mullet Mugil cephalus were 4 to 6 in. Losses were high, so the survivors may not be representative of their species. The tilapia engaged in courtship displays even though the individual tanks were grouped by sex; the mullet were immature.

An opaque box, $12 \times 12 \times 12$ in., containing an Ames key and feeder (Ames, 1967), was placed over the home tank to start each session. One side was open to permit observation. The Ames key was more sensitive and reliable than a suspended paddle (Bitterman, 1966). It has no key bounce and eliminates edge nibbling. The locus of feeding is set by the food cup, delivery is dependable, and the amount of

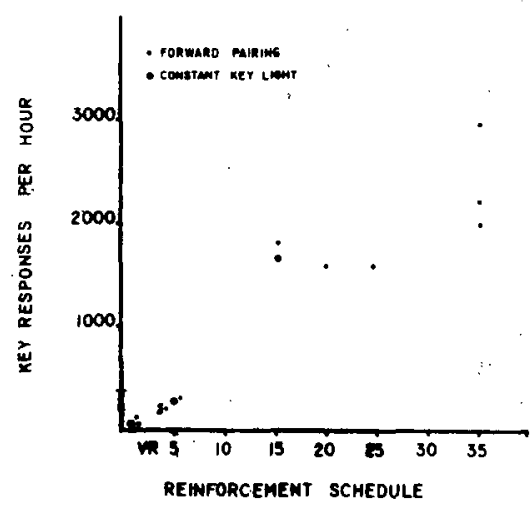

Fig. 1. Performance during Session 20 of tilapia trained by forward pairing (FP) or by constant key light (CKL). The stars designate fish exposed to 10 CKL sessions but autoshaped subsequently by FP.
Brown \& Jenkins (1968) describe a procedure assuring that pigeons will self-shape a key response. At irregular intervals, a pigeon key was lighted for a few seconds. When the light went off, an illuminated grain tray was available for $4 \mathrm{sec}$. No key response was required; any response to the lit key activated the tray, while a response to the unlit key postponed onset of the key light. Thirty-six pigeons learned the key response with a mean of 45 trials and fewer than four errors each.

Sidman \& Fletcher (1968) demonstrated a similar technique with four thesus monkeys, all of which pressed a key within 60 trials. Power, Saunders, and Thompson exposed 10 rats to autoshaping. Nine acquired the response with a mean of six sessions; there was no significant difference between autoshaping and handshaping. 